\title{
Characteristics of Pulsed Current Bead on Plate Deposit in Flux Cored GMAW Process
}

\author{
P. K. GHOSH and B. K. RAI
}

Welding Research Laboratory, Department of Mechanical and Industrial Engineering, University of Roorkee, Roorkee-247667, India.

(Received on September 13, 1995; accepted in final form on January 18, 1996)

\begin{abstract}
The influences of pulse parameters, arc voltage and welding speed on the characteristics of weld beads deposited on C-Mn steel plate by flux cored GMAW process have been studied. The pulse parameters are found to affect the microstructure and porosity content of weld bead and the width of HAZ. The arc voltage, affecting the $I_{\mathrm{p}}$ and $I_{\mathrm{b}}$ also found to influence the characteristics of weld bead significantly. The porosity content of weld bead and the width and hardness of $\mathrm{HAZ}$ are found to have a significant correlationship with a factor, defined as a function of $I_{\mathrm{p}}, I_{\mathrm{b}}, f$ and $t_{\mathrm{b}}$. The influence of welding speed has been found of usual nature. It is marked that a right selection of pulse parameters can improve the weld quality over that observed in case of continuous current GMAW.
\end{abstract}

KEY WORDS: pulse GMAW; flux cored wire; bead on plate; microstructure; porosity; HAZ; factor $\phi$ as a function of pulse parameters; correlation of $\phi$ and bead characteristics.

\section{Introduction}

The use of pulse current Gas Metal Arc welding (GMAW) has gathered considerable attention of welding technologists due to its number of merits such as better control over metal transfer and heat input, improved weld quality and better performance in positional welding as compared to those observed in case of conventional continuous current GMAW process. However, the exploitation of the merits of pulsed current GMAW process is largely dependent upon right selection of pulse parameters, like mean current $\left(I_{\mathrm{m}}\right)$, peak current $\left(I_{\mathrm{p}}\right)$, base current $\left(I_{\mathrm{b}}\right)$, pulse duration $\left(t_{\mathrm{p}}\right)$ and pulse frequency $(f)$ as they affect the microstructure of weld and HAZ as well as porosity content of the weld due to their influence on weld thermal cycle ${ }^{1)}$ and arc characteristics. The criticality in selection of pulse parameters, arising out of dependency of pulse parameters on each other, can be reduced by acquiring knowledge over the influence of different pulse parameters on various characteristics of weld deposit. In this regard a number of work $^{2-6)}$ involving the pulse current GMAW using soild filler wires of ferrous and nonferrous materials, are reported so far. In recent years the growing demands of GMAW using flux cored wire, in place of soild filler wire, due to its advantage of economy with high deposition rate, ${ }^{7,8)}$ improved weld quality ${ }^{9}$ and reasonable performance in positional welding ${ }^{8)}$ obviously raise the curiosity about its performance under pulsed current welding. Some efforts in this direction have already been initiated, ${ }^{10)}$ but hardly any result has been reported so far identifying the influence of pulse parameters on the microstructure and porosity content of the pulse current GMA weld as well as the characteristics of its heat affected zone (HAZ).

In this investigation an effort has been made to study the influence of various pulse parameters, arc voltage and welding speed on the above aspects during bead on plate deposition by pulse current GMAW process using a flux cored wire. The characteristics of weld bead obtained under pulse current have also been compared with those observed under conventional continuous current flux cored GMAW.

\section{Experimental}

The deposition of weld bead on $12 \mathrm{~mm}$ thick base plate of $\mathrm{C}-\mathrm{Mn}$ steel having ferrite-pearlite microstructure, as shown in Fig. 1, was carried out by pulsed current and conventional continuous current GMAW process using $1.2 \mathrm{~mm}$ diameter basic flux cored filler wire of specification AWS E 70 T-5. The chemical

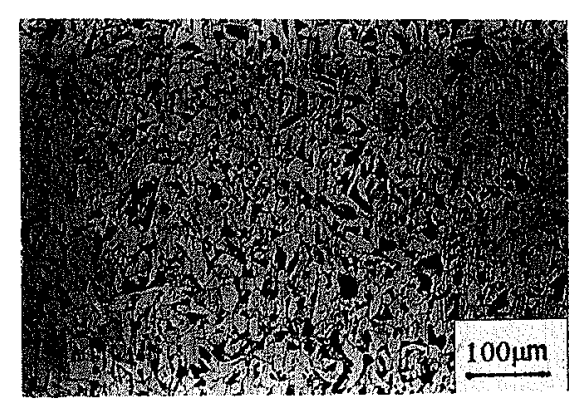

Fig. 1. Microstructure of the base metal. 
Table 1. Chemical compositions of base metal and filler wire. $(\mathrm{wt} \%)$

\begin{tabular}{lccccc}
\hline & $\mathrm{C}$ & $\mathrm{Mn}$ & $\mathrm{Si}$ & $\mathrm{P}$ & $\mathrm{S}$ \\
\hline Base metal & 0.175 & 1.09 & 0.04 & 0.009 & 0.015 \\
All weld metal* & $0.05-0.06$ & $1.0-1.5$ & $0.6(\max )$ & $0.03(\max )$ & $0.03(\max )$ \\
\hline
\end{tabular}

* As per manufacturer.

Table 2. Welding parameters.

\begin{tabular}{|c|c|c|c|c|c|c|c|}
\hline $\begin{array}{l}\text { Mean } \\
\text { current } \\
\text { (A) }\end{array}$ & $\begin{array}{c}\text { Pulse } \\
\text { frequency } \\
(\mathrm{Hz})\end{array}$ & $\begin{array}{l}\text { Pulse } \\
\text { duration } \\
\text { (ms) }\end{array}$ & $\begin{array}{c}\text { Base } \\
\text { current } \\
\text { (A) }\end{array}$ & $\begin{array}{l}\text { Peak } \\
\text { current } \\
\text { (A) }\end{array}$ & $\begin{array}{c}\text { Arc } \\
\text { voltage } \\
\text { (V) }\end{array}$ & $\begin{array}{c}\text { Welding } \\
\text { speed } \\
(\mathrm{mm} / \mathrm{s})\end{array}$ & $\phi$ \\
\hline 100 & 0 & - & - & - & 24 & 3 & - \\
\hline 100 & 25 & 6.0 & 90 & 271 & 24 & 3 & 0.282 \\
\hline 100 & 50 & 6.0 & 70 & 250 & 24 & 3 & 0.196 \\
\hline 100 & 100 & 6.0 & 30 & 212 & 24 & 3 & 0.057 \\
\hline 100 & 50 & 4.5 & 90 & 260 & 24 & 3 & 0.268 \\
\hline 100 & 50 & 7.5 & 60 & 272 & 24 & 3 & 0.138 \\
\hline 100 & 50 & 6.0 & 70 & 280 & 21 & 3 & 0.175 \\
\hline 100 & 50 & 6.0 & 90 & 233 & 27 & 3 & 0.270 \\
\hline 100 & 50 & 6.0 & 70 & 255 & 24 & 1.67 & 0.192 \\
\hline 100 & 50 & 6.0 & 75 & 243 & 24 & 4.33 & 0.216 \\
\hline 150 & 0 & - & - & - & 24 & 3 & - \\
\hline 150 & 25 & 6.0 & 120 & 367 & 24 & 3 & 0.278 \\
\hline 150 & 50 & 6.0 & 110 & 332 & 24 & 3 & 0.232 \\
\hline 150 & 100 & 6.0 & 70 & 300 & 24 & 3 & 0.093 \\
\hline 150 & 50 & 4.5 & 120 & 294 & 24 & 3 & 0.316 \\
\hline 150 & 50 & 7.5 & 100 & 362 & 24 & 3 & 0.173 \\
\hline 150 & 50 & 6.0 & 100 & 356 & 21 & 3 & 0.197 \\
\hline 150 & 50 & 6.0 & 120 & 320 & 27 & 3 & 0.263 \\
\hline 150 & 50 & 6.0 & 100 & 340 & 24 & 1.67 & 0.206 \\
\hline 150 & 50 & 6.0 & 110 & 332 & 24 & 4.33 & 0.232 \\
\hline 200 & 0 & - & - & - & 24 & 3 & - \\
\hline 200 & 25 & 6.0 & 170 & 380 & 24 & 3 & 0.380 \\
\hline 200 & 50 & 6.0 & 120 & 360 & 24 & 3 & 0.233 \\
\hline 200 & 100 & 6.0 & 70 & 327 & 24 & 3 & 0.086 \\
\hline 200 & 50 & 4.5 & 160 & 347 & 24 & 3 & 0.357 \\
\hline 200 & 50 & 7.5 & 110 & 372 & 24 & 3 & 0.185 \\
\hline 200 & 50 & 6.0 & 120 & 404 & 21 & 3 & 0.208 \\
\hline 200 & 50 & 6.0 & 140 & 327 & 27 & 3 & 0.300 \\
\hline 200 & 50 & 6.0 & 130 & 370 & 24 & 1.67 & 0.246 \\
\hline 200 & 50 & 6.0 & 130 & 362 & 24 & 4.33 & 0.252 \\
\hline
\end{tabular}

compositions of the base plate and filler wire are shown in Table 1. During welding the shielding gas as a mixture of argon- $20 \%$ carbon dioxide was used at a flow rate of $20 \mathrm{l} / \mathrm{min}$ and the electrode stick-out was kept as $20 \mathrm{~mm}$. The pulse current welding was carried out at different mean current, where the pulse frequency and pulse duration were varied at a given arc voltage and welding speed. The weld beads were also deposited by varying the arc voltage and welding speed at different mean currents, where the pulse frequency and duration as well as welding speed or arc voltage, as applicable respectively, were kept constant. For a comparative study the beads were also deposited by continuous current $(0 \mathrm{~Hz})$ process using welding currents same as the mean currents used in the pulse current process. During pulsed current welding the pulse characteristics were monitored using a digital oscilloscope and the peak $\left(I_{\mathrm{p}}\right)$ and base $\left(I_{\mathrm{b}}\right)$ currents were measured with the help of a scanner moving on the pulse pattem held at the CRO screen of

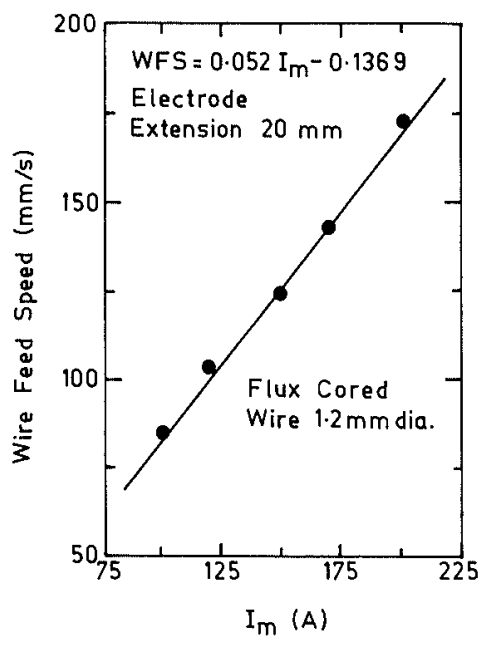

Fig. 2. Relationship of wire feed speed and mean current.

the oscilloscope. The detail of the welding parameters has been presented in Table 2. The mean current was varied with the wire feed rate as shown in Fig. 2.

The transverse section of the weld beads, collected from the central part of the deposit, assuring a stable welding, was metallographically polished and etched by $2 \%$ nital solution. The microstructures of weld deposit and HAZ were studied under optical microscope.

The porosity content of weld deposit was estimated under optical microscope by standard point counting method ${ }^{11)}$ using the polished unetched samples. The area fraction of the porosity, appeared as approximately round shape black spots on the matrix, was estimated at suitable $^{11)}$ magnification $(\times 100)$ and reported in volume fraction, as in this case it is closely a linear function of area fraction.

The width of HAZ, identified as the zone having considerable change in microstructure of base metal, with reference to the fusion line was measured under optical microscope with the help of a microscale attached to it. The Vicker's microhardness of HAZ at a distance of $0.3 \mathrm{~mm}$ from the fusion line was measured at a load of $50 \times 10^{-3} \mathrm{~N}$. The Vicker's hardness of weld deposit was also measured at its central part by using a load of $50 \mathrm{~N}$.

\section{Results and Discussions}

\subsection{Weld Bead}

\subsubsection{Microstructure}

The typical microstructures of continuous current GMA weld beads, deposited at the welding currents of 100 and $200 \mathrm{~A}$, have been shown in Figs. 3(a) and 3(b), respectively, where the arc voltage and welding speed are kept as $24 \mathrm{~V}$ and $3 \mathrm{~min} / \mathrm{s}$, respectively. The weld beads are found to have cast dendritic microstructure containing bright (ferrite) and dark phases. The micrographs show that the increase of welding current reduces the columnar growth of dendrites in the matrix. The dark region of the microstructure of both the continuous current and pulse current (discussed below) weld beads, revealed in overall view of the weld bead at lower magnification, has been found to consist of bainite at 
higher magnification. However, the morphology of the bainite was changed with the variation in welding parameters as typically depicted in Figs. 4(a) and 4(b).

At a given pulse duration, arc voltage and welding speed of $6.0 \mathrm{~ms}, 24 \mathrm{~V}$ and $3 \mathrm{~mm} / \mathrm{s}$ respectively the effect of pulse frequency on the microstructure of pulse current GMA weld bead, deposited at the mean currents of 100 and $200 \mathrm{~A}$, has been shown in Fig. 5. The micrographs reveal that at a given mean current the increase of pulse frequency coarsens the microstructure, especially with respect to the growth of dendrites. It is also observed that at a given pulse frequency the coarsening of microstructure is encouraged with the increase of mean current because of the enhancement of energy input.

At a given pulse frequency, arc voltage and welding speed of $50 \mathrm{~Hz}, 24 \mathrm{~V}$ and $3 \mathrm{~mm} / \mathrm{s}$ respectively the effect
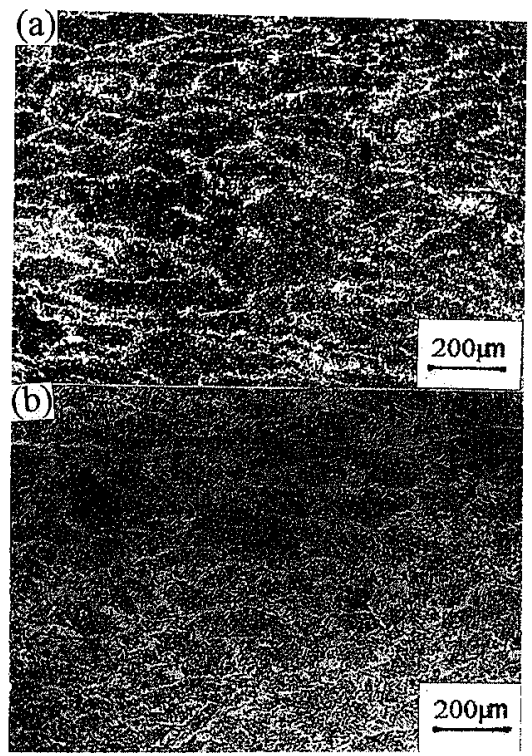

Fig. 3. Effect of welding currents (a) 100 and (b) $200 \mathrm{~A}$ on the microstructure of continuous current weld deposit. of pulse duration on the microstructures of pulse current weld beads, deposited at different mean currents of 100 and $200 \mathrm{~A}$, has been shown in Fig. 6. The micrographs show that at a given mean current the increase of pulse duration significantly coarsens the microstructure of weld bead due to reduction in cooling rate of weld deposit. The reduction of cooling rate results from the enhancement of super heating of weld deposit resulting from increase in peak current at higher pulse duration. At a given pulse duration the increase of mean current has as usual been found to coarsens the microstructure of weld bead.

At a given pulse frequency, pulse duration and welding

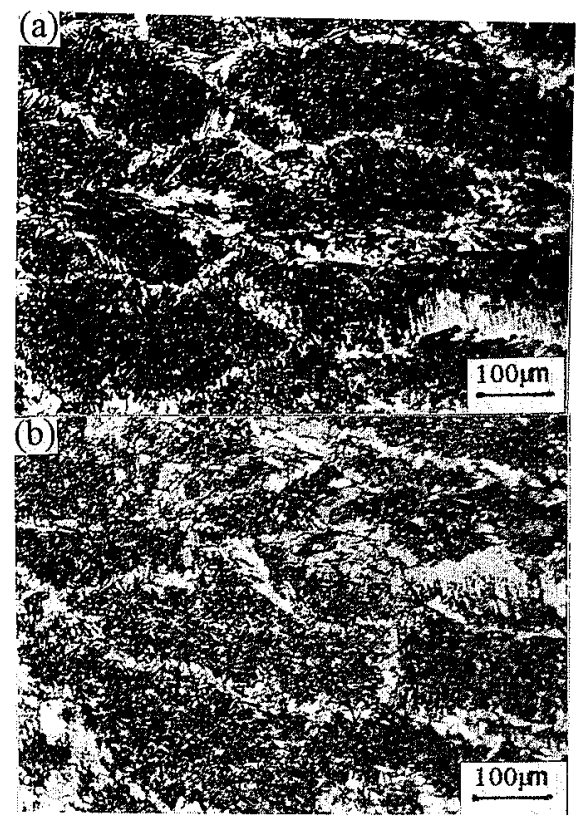

Fig. 4. Typical microstructures of weld metal showing the presence of bainite of different morphology at different welding parameters; (a) $I_{\mathrm{m}}=100 \mathrm{~A}, f=50 \mathrm{~Hz}, \mathrm{WS}=$ $3 \mathrm{~mm} / \mathrm{s}$ and arc voltage $=24 \mathrm{~V}$ and (b) $I_{\mathrm{m}}=200 \mathrm{~A}$, $f=50 \mathrm{~Hz}, \mathrm{WS}=3 \mathrm{~mm} / \mathrm{s}$ and arc voltage $=24 \mathrm{~V}$.



Fig. 5. At different mean currents effect of pulse frequency on the microstructure of weld metal. 


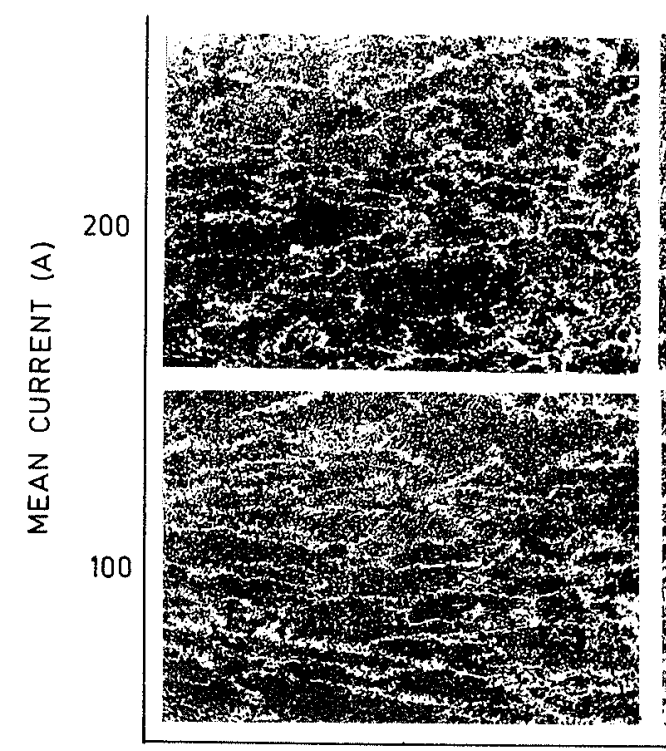

4.5

PULSE DURATION (ms)
Fig. 6.

At different mean currents effect of pulse duration on the microstructure of weld metal.

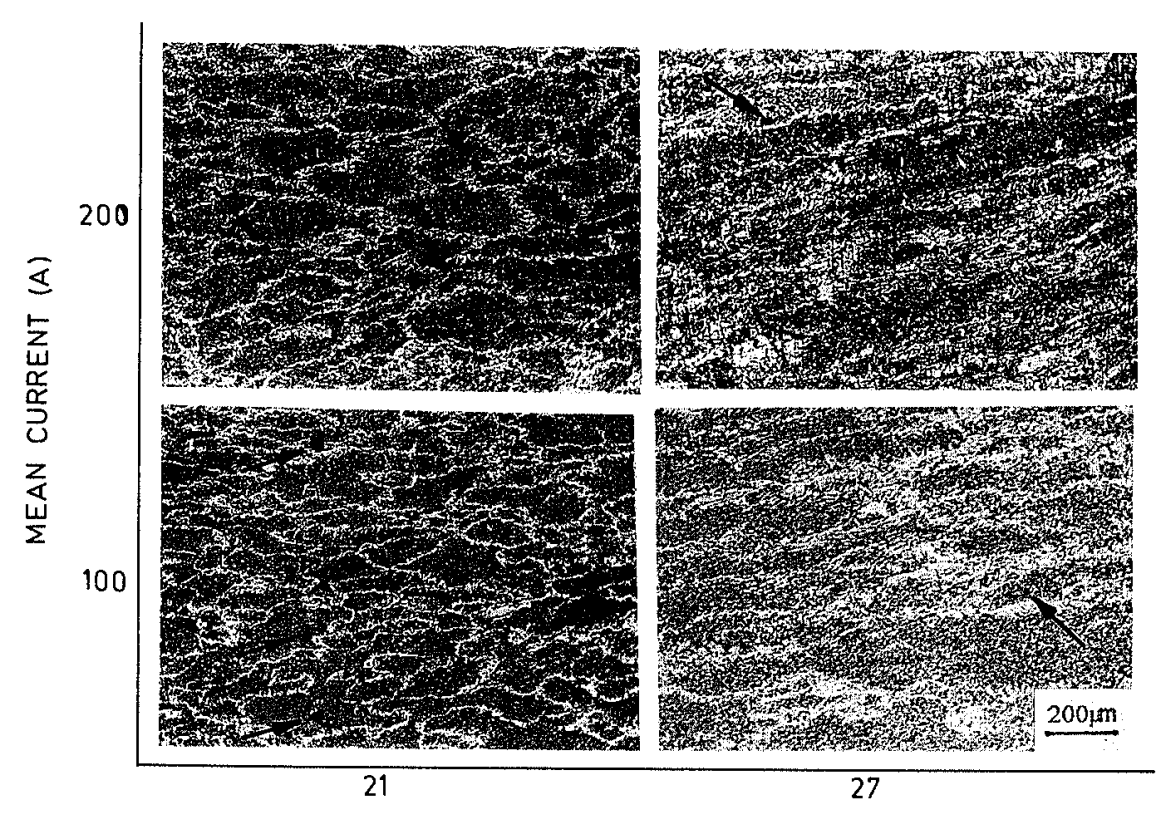

Fig. 7.

At different mean currents effect of arc voltage on the microstructure of weld metal.

ARC VOLTAGE (V)

speed of $50 \mathrm{~Hz}, 6.0 \mathrm{~ms}$ and $3 \mathrm{~mm} / \mathrm{s}$ respectively the influence of arc voltage on the microstructure of weld beads, deposited at different mean currents of 100 and $200 \mathrm{~A}$, has been shown in Fig. 7. The figure shows that at a given mean current the increase of arc voltage refines the microstructure of weld deposit. At a given arc voltage the increase of mean current coarsens the microstructure of the matrix more significantly at the lower arc voltage of $21 \mathrm{~V}$. A comparison of the microstructures of continuous current (Fig. 3) and pulse current (Figs. 5-7) weld deposits reveals that during deposition at a given mean current or wire feed speed the pulse current welding generally results a comparatively coarser microstructure, especially at higher pulse frequency and pulse duration. However, the pulse current welding carried out at a higher arc voltage of about $27 \mathrm{~V}$ may be beneficial for producing a comparatively finer microstructure of weld deposit.

At a given pulse frequency, pulse duration and arc voltage of $50 \mathrm{~Hz}, 6.0 \mathrm{~ms}$ and $24 \mathrm{~V}$ respectively the influence of welding speed on the microstructure of weld beads, deposited at different mean currents of 100 and $200 \mathrm{~A}$, has been shown in Fig. 8. The figure shows that at a given mean current the decrease of welding speed significantly coarsens the growth of dendrite as well as transforms more proeutectoid ferrite in the matrix. These are attributed to a significant enhancements in energy input, resulting a slow cooling of weld bead.

\subsubsection{Porosity}

The weld beads deposited at different welding parameters, in both the continuous current and pulse current welding processes are, found to have certain amount of porosity. The pores observed in the micrographs are 


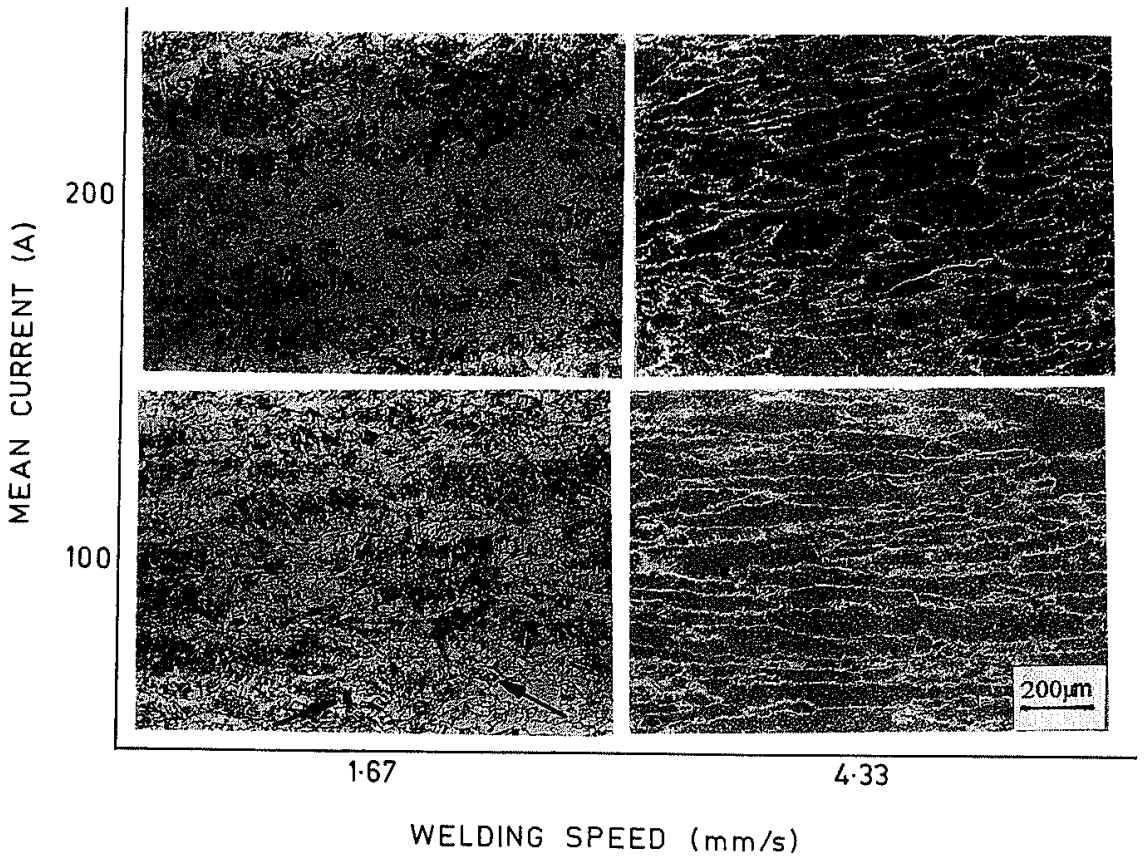

Fig. 8.

At different mean currents effect of welding speed on the microstructure of weld metal.

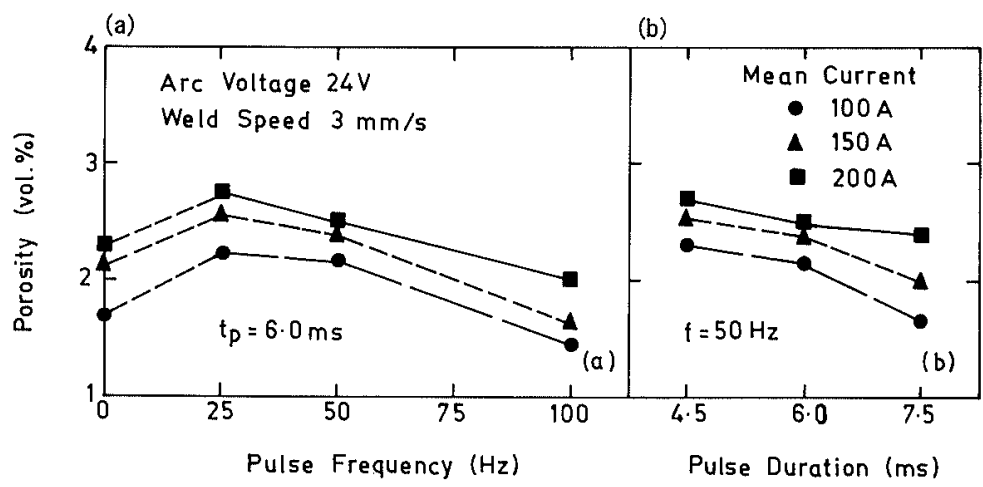

Fig. 9.

At different mean currents effects of (a) pulse frequency and (b) pulse duration on the porosity content of weld metal.

marked by arrow. However, the amount of porosity in weld beads are found to vary with the change in welding parameters.

The effects of pulse frequency and pulse duration on the porosity of weld bead, deposited at different mean currents of 100, 150 and 200 A, are shown in Figs. 9(a) and 9(b), respectively. Figure 9(a) shows that at a given pulse frequency the increase of mean current enhances the porosity content of weld deposit. During pulse current welding at any mean current the use of low pulse frequency of $25 \mathrm{~Hz}$ results a larger amount of porosity in the weld than that observed in the continuous current $(0 \mathrm{~Hz})$ weld. However, a further increase of pulse frequency upto $100 \mathrm{~Hz}$ has been found to reduce the porosity content of the weld. At a given mean current the use of high pulse frequency of $100 \mathrm{~Hz}$ has been found to lower the porosity level below that observed in the continuous current weld. Figure $9(\mathrm{~b})$ shows that at a given mean current the increase of pulse duration upto $7.5 \mathrm{~ms}$ reduces the porosity content of weld deposit to a level, which is comparable to the porosity content of continuous current weld. At a given pulse duration the increase of mean current has as usual been found to enhance the porosity content of the weld and it is found to be comparatively more pronounced at higher duration of $7.5 \mathrm{~ms}$.

Effect of arc voltage on the porosity content of weld

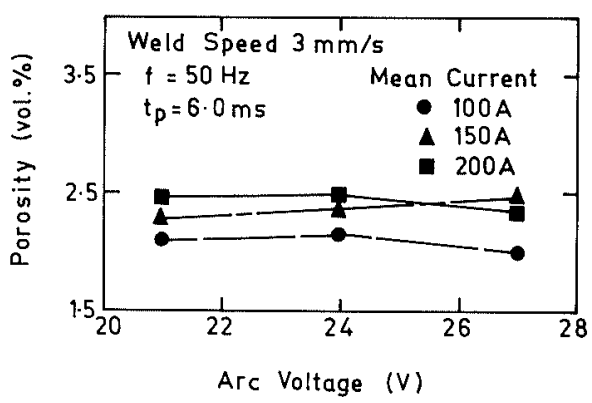

Fig. 10. Effect of arc voltage on the porosity content of weld metal.

bead has been shown in Fig. 10. The figure shows that at a given mean current the variation of arc voltage does not influence the porosity content of the weld significantly. During pulse current welding at a low mean current of $100 \mathrm{~A}$ the increase of welding speed has been found to enhance the porosity content of weld deposit (Fig. 11). But the rate of increase of porosity with the welding speed has been found to be lowered with the increase of mean current and finally at a high mean current of $200 \mathrm{~A}$ the increase of welding speed has been found to reduce the porosity content of weld bead.

In GMAW process the porosity formation at weld deposit is primarily dependent upon contamination of the consumables and shielding jacket. In this investi- 
gation the quality and flow rate of the shielding gas mixture and the quality of filler wire are kept constant. During continuous current welding the increase in porosity content of weld bead with the increase of welding current may be attributed to the enhancement of heat input causing a larger dissolution of available hydrogen in molten weld pool due to its higher supper heating. But this phenomenon does not justifies the results of pulse current welding, where at a given mean current or wire feed speed the porosity content of weld deposit varies significantly with a change in pulse characteristics. Thus, it may be assumed that during pulsed current welding the variation in porosity content of weld deposit is primarily attributed to a variation in contamination of shielding gas jacket due to air aspiration in it, resulted form the nature of fluctuation of arc pressure under pulsed current. The behaviour of arc is largely governed by the pulse characteristics such as $I_{\mathrm{p}}$, $I_{\mathrm{b}}$ and $t_{\mathrm{b}}$. Table 2 shows that $I_{\mathrm{p}}$ and $I_{\mathrm{b}}$ are significantly

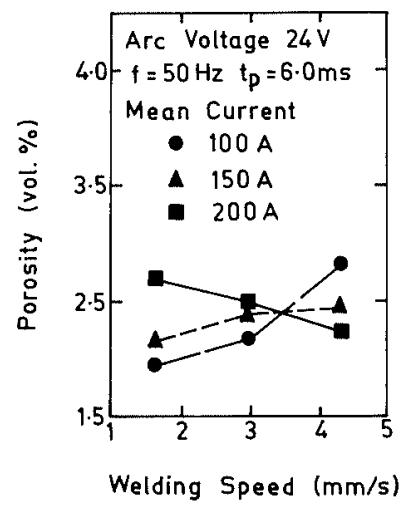

Fig. 11. Effect of welding speed on the porosity content of weld metal.

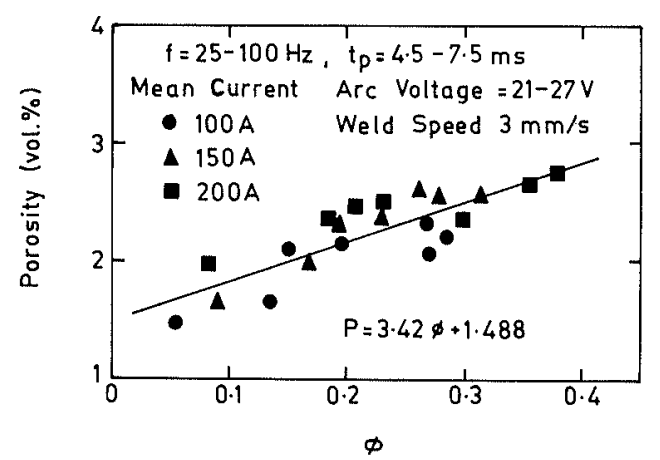

Fig. 12. Influence of $\phi$ on the porosity content of weld metal. dependent on $I_{\mathrm{m}}, f, t_{\mathrm{p}}$ and arc voltage, where the $t_{\mathrm{p}}$ is a function of $f$ and $t_{\mathrm{b}}$ (pulse off time). Thus, it is clear that porosity content of weld deposit is primarily controlled by a combined effect of these pulse parameters. Hence, for controlling the porosity content of weld deposit by right selection of pulse parameters, it is imperative to know the summarized influence of all these pulse parameters on porosity content of weld bead. In this context it may be justified to correlate the porosity content of weld bead with an empirical factor $\phi$ defined $^{12)}$ as

$$
\phi=\left[\left(f t_{\mathrm{b}} I_{\mathrm{b}}\right) / I_{\mathrm{p}}\right]
$$

The porosity content of weld deposit has been found to enhance linearly (Fig. 12) with the increase of $\phi$ where, the factor $\phi$ varied with a change in pulse frequency, pulse duration and arc voltage in the range of 25-100 $\mathrm{Hz}, 4.5-7.5 \mathrm{~ms}$ and $21-27 \mathrm{~V}$ respectively at different mean currents of 100,150 and $200 \mathrm{~A}$. It is also marked that the porosity content of weld bead is practically independent of $I_{\mathrm{m}}$ but, dependent upon pulse characteristics.

The lowering of porosity with the increase of welding speed, at high mean current of $200 \mathrm{~A}$, is primarily attributed to the decrease of heat input as it is observed earlier during reduction of mean current. But at the lower mean currents the increase of porosity with the increase of welding speed may have happened due to some instability in shielding jacket resulted at higher welding speed, which is reduced with the increase of mean current because of stronger arc and higher velocity of plasma.

\subsubsection{Hardness}

The effect of pulse frequency and pulse duration on the hardness of weld bead deposited at different mean currents of 100, 150 and 200 A has been shown in Figs. 13(a) and 13(b), respectively. Figure 13(a) shows that at a given mean current the increase of pulse frequency reduces the hardness of weld deposit and becomes significantly lower than that of continuous current deposit, when the pulse frequency is raised to $100 \mathrm{~Hz}$. Figure 13(b) shows that at a given mean current the increase of pulse duration upto $7.5 \mathrm{~ms}$ also reduces the hardness of weld deposit significantly in comparison to that of the continuous current deposit. However, during pulse current welding at a given mean current, the increase of arc voltage or welding speed has been found to enhance the hardness of weld deposit significantly as

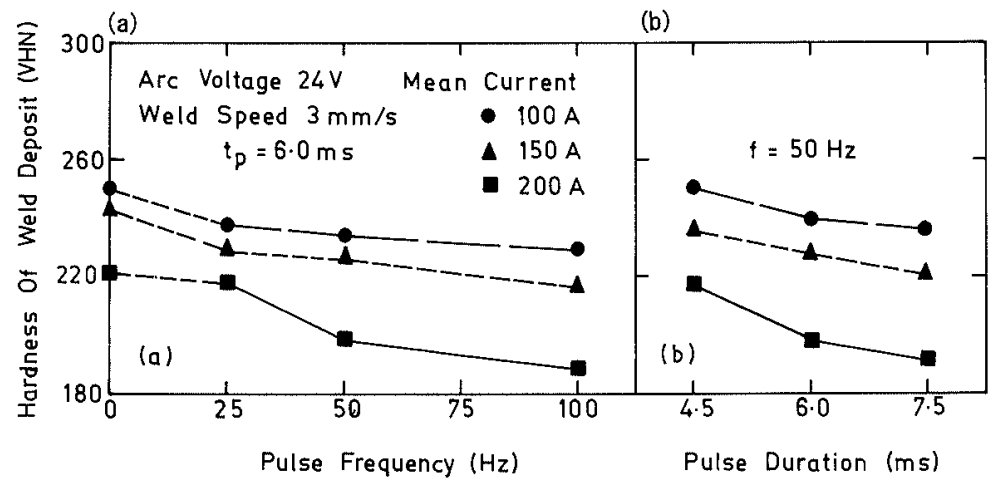

Fig. 13.

At different mean currents effect of (a) pulse frequency and (b) pulse duration on the hardness of weld metal. 
shown in Figs. 14 and 15, respectively.

The variation in hardness of weld bead with the change in pulse frequency, pulse duration, arc voltage and welding speed is in agreement to the microstructure of the respective weld bead as discussed earlier, which infers that the coarsening of microstructure of weld bead reduces its hardness. In all the Figs. 13 to 15 it is also noted that at a given pulse frequency, pulse duration or arc voltage the increase of mean current from 100 to $150 \mathrm{~A}$ relatively reduces the hardness of weld bead followed by a significant decrease in it with a further increase of mean current to $200 \mathrm{~A}$, especially at higher pulse frequency or pulse duration and lower arc voltage. The decrease in hardness of weld bead with the increase of mean current is well understood due to increase in heat input causing coarsening of microstructure as it is also observed in case of continuous current $(0 \mathrm{~Hz})$ deposit (Fig. 13(a)). At a given pulse frequency and

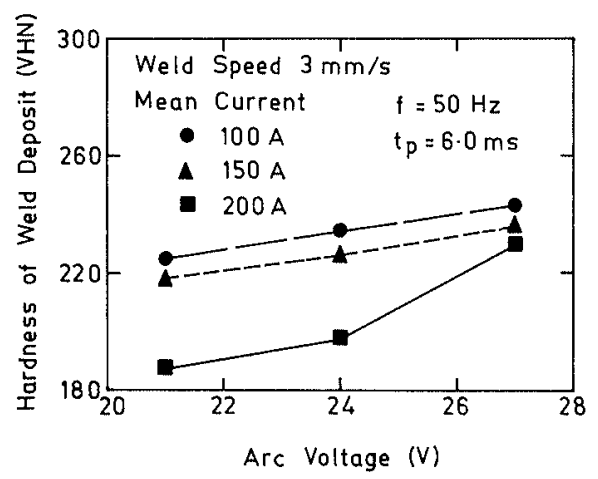

Fig. 14. Effect of are voltage on the hardness of weld metal.

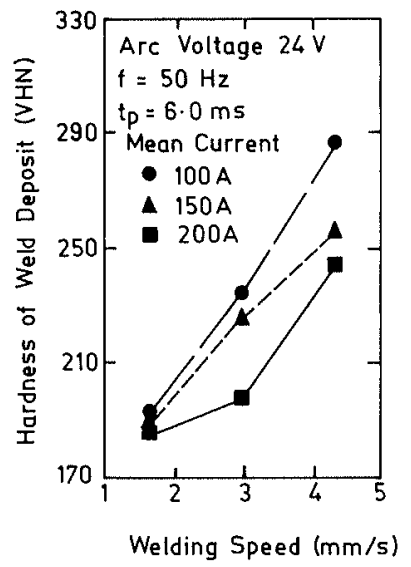

Fig. 15. Effect of welding speed on the hardness of weld metal. duration, the increase of hardness of weld bead with the increase of welding speed is well known but, the similar behaviour of hardness of weld bead with the increase of arc voltage, observed in contrast to that generally experienced in case of conventional GMA welding process, possibly caused by the change in pulse characteristics $\left(I_{\mathrm{p}}\right.$ and $\left.I_{\mathrm{b}}\right)$ with the arc voltage affecting the weld thermal cycle.

\subsection{Heat Affected Zone}

\subsubsection{Width of HAZ}

The influence of pulse frequency and pulse duration on the width of $\mathrm{HAZ}$, resulted during deposition of weld bead at different mean currents of 100,150 and $200 \mathrm{~A}$, has been shown in Figs. 16(a) and 16(b), respectively. Figures 16(a) and 16(b) show that at a given mean current the increase of pulse frequency or pulse duration relatively enhances the width of $\mathrm{HAZ}$. At a given mean current the width of HAZ of pulse current weld bead has been found relatively lower than that of continuous current weld, when the pulse frequency or pulse duration is kept low at $25 \mathrm{~Hz}$ or $4.5 \mathrm{~ms}$ respectively. However, the width of HAZ of pulse current weld bead, deposited at higher pulse frequency or pulse duration of $100 \mathrm{~Hz}$ and $7.5 \mathrm{~ms}$ respectively, has been found to be relatively high or comparable to that of continuous current weld bead.

At a given mean current the effect of arc voltage and welding speed on the width of HAZ of pulse current weld bead has been shown in Figs. 17 and 18, respectively. The figures depict that at a given mean current the increase of arc voltage and welding speed significantly enhances and reduces the width of $\mathrm{HAZ}$, respectively. It is also marked that during pulse current deposition at any mean current the use of low arc voltage and high welding speed of $21 \mathrm{~V}$ and $4.33 \mathrm{~mm} / \mathrm{s}$ respectively results a HAZ significantly narrower than that of continuous current (Fig. 16(a)) weld. But the keeping of a high arc voltage and low welding speed of $27 \mathrm{~V}$ and $1.67 \mathrm{~mm} / \mathrm{s}$ respectively gives a considerably wider HAZ than that of continuous current weld.

In all the figures (Figs. 16-18) it is observed that the increase of mean current enhances the width of $\mathrm{HAZ}$ primarily due to increase in heat input. This is also found true during reduction of width of $\mathrm{HAZ}$ with the increase of welding speed. However, at a given mean current and welding speed the increase in width of HAZ with the increase of pulse frequency or pulse duration may be

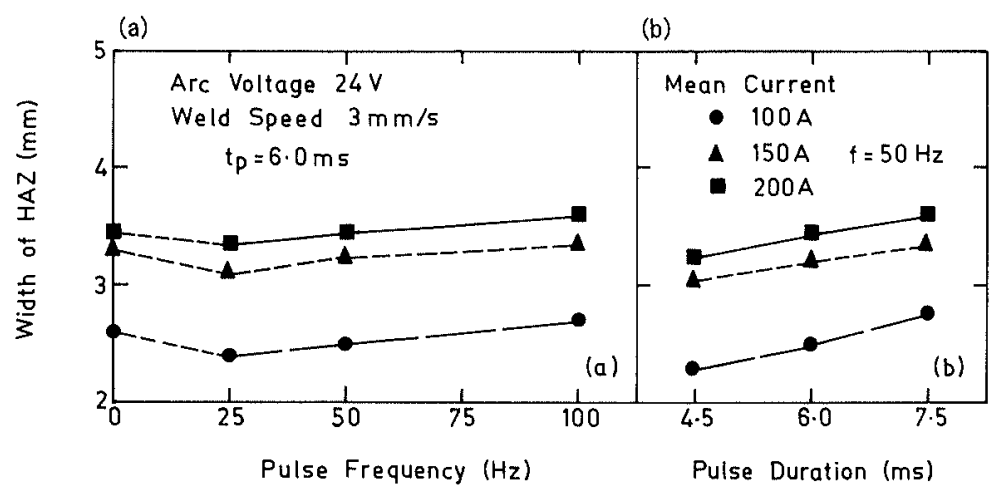

Fig. 16.

At different mean currents effects of (a) pulse frequency and (b) pulse duration on the width of HAZ. 


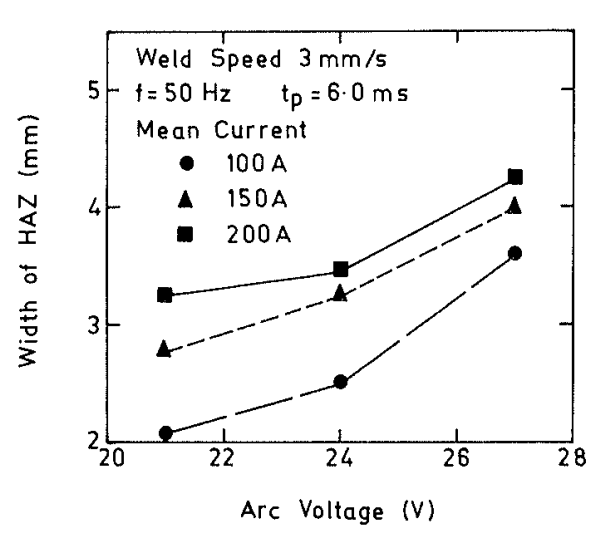

Fig. 17. Effect of arc voltage on the width of HAZ.

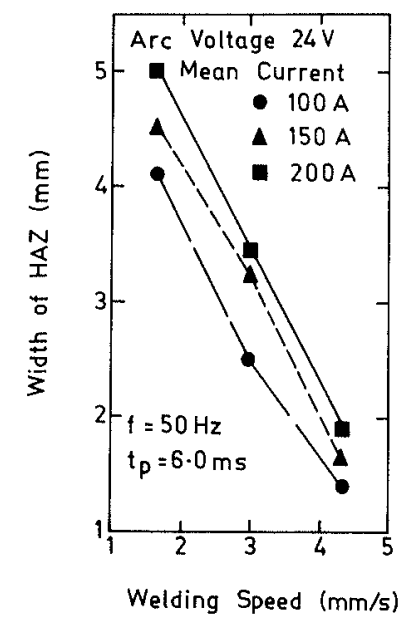

Fig. 18. Effect of welding speed on the width of HAZ.

primarily attributed to the increase of super heating of weld deposit and/or heat build up in the weld pool, which is a function of $I_{\mathrm{p}}, I_{\mathrm{b}}, f$ and $t_{\mathrm{b}}$. Thus, here also it may be justfied to correlate the width of HAZ of pulse current deposit with the factor $\phi$. The Fig. 19 shows that at a given mean current the width of $\mathrm{HAZ}$ reduces linearly with the increase of $\phi$, where the arc voltage is kept constant as $24 \mathrm{~V}$. The arc voltage also considerably influences the $I_{\mathrm{p}}$ and $I_{\mathrm{b}}$ and consequently the $\phi$. Inspite of that it can not be considered along with the pulse frequency or duration to evaluate their influence on the width of $\mathrm{HAZ}$, because the arc voltage not only affect the HAZ by influencing the $I_{\mathrm{p}}$ and $I_{\mathrm{b}}$ but also by changing the arc length. The expression of $\phi$ does not involve any physical term considering the arc length. Thus, in case of variation in arc voltage the effect of $\phi$ on the width of HAZ is studied separately and it is observed that the width of HAZ linearly rises with the increase of $\phi$ (Fig. 20), more significantly than that observed in Fig. 19 , where the effect of mean current becomes practically insignificant.

\subsubsection{Hardness of $\mathrm{HAZ}$}

The hardness of HAZ is primarily affected by the variation in coarsening of its microstructure caused by a change in weld thermal cycle. The effect of pulse frequency and pulse duration on the hardness of $\mathrm{HAZ}$, resulting from deposition of weld beads at different mean

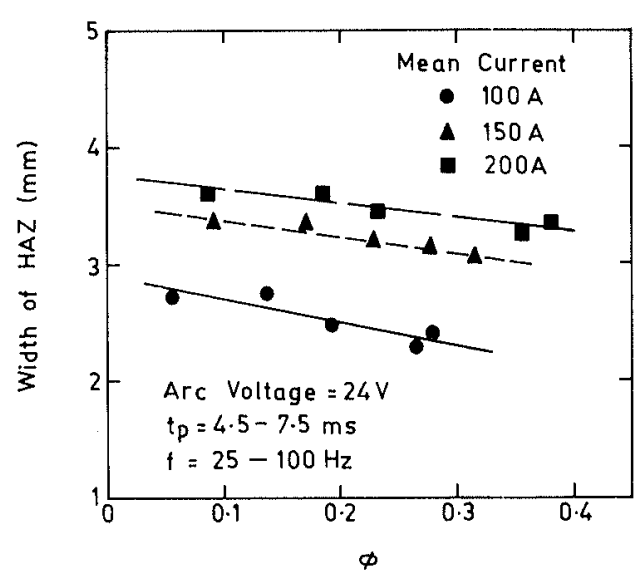

Fig. 19. At a given arc voltage influence of $\phi$ on the width of HAZ.

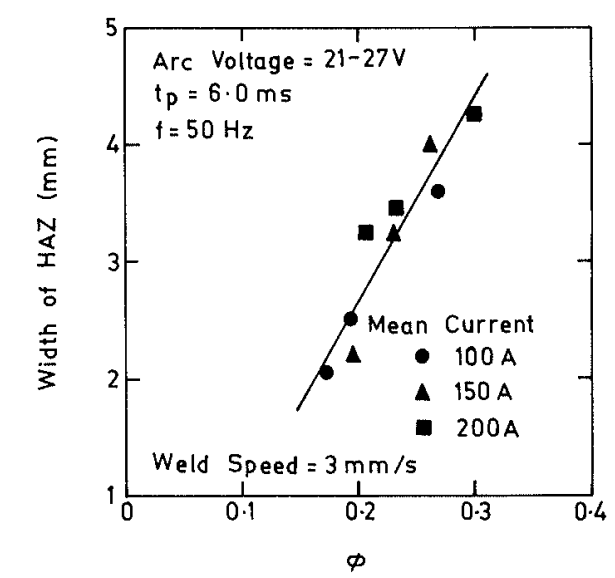

Fig. 20. Under varying arc voltage influence of $\phi$ on the width of HAZ.

currents of 100,150 and $200 \mathrm{~A}$, has been shown in Figs. 21(a) and 21(b), respectively. The figures show that at a given mean current the increase of both the pulse frequency and pulse duration reduces the hardness of HAZ. It is also observed that at a given mean current the increase of arc voltage and welding speed significantly reduces (Fig. 22) and enhances (Fig. 23) respectively the hardness of HAZ. However, the Figs. 21 to 23 depict that at a given mean current the pulse current weld beads generally result a comparatively softer HAZ than that of the continuous $(0 \mathrm{~Hz})$ current weld bead (Fig. 21).

At a given pulse parameter the increase of mean current and arc voltage and the decrease of welding speed have been found to reduce the hardness of HAZ primarily due to coarsening of microstructure caused by the increase of energy input. But again at a given mean current the reduction in hardness of HAZ with the increase of pulse frequency or duration possibly attributed to an increase in super heating and/or heat build up in the weld pool, governed by the combined influence of $I_{\mathrm{p}}, I_{\mathrm{b}}, f$ and $t_{\mathrm{b}}$. The correlation of $\phi$ with the hardness of HAZ (Fig. 24) show that at a given mean current the increase of $\phi$, due to variation of pulse frequency and duration, relatively enhances the hardness of $\mathrm{HAZ}$ linearly. But, at a given pulse parameter the increase of $\phi$ with a change in arc voltage, affecting the $I_{\mathrm{p}}$ and $I_{\mathrm{b}}$, 


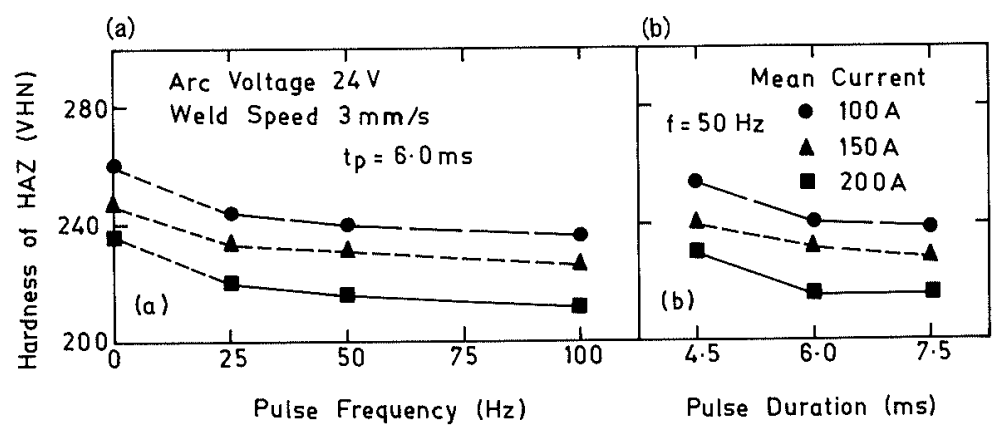

Fig. 21.

At different mean currents of (a) pulse frequency and (b) pulse duration on the hardness of HAZ.

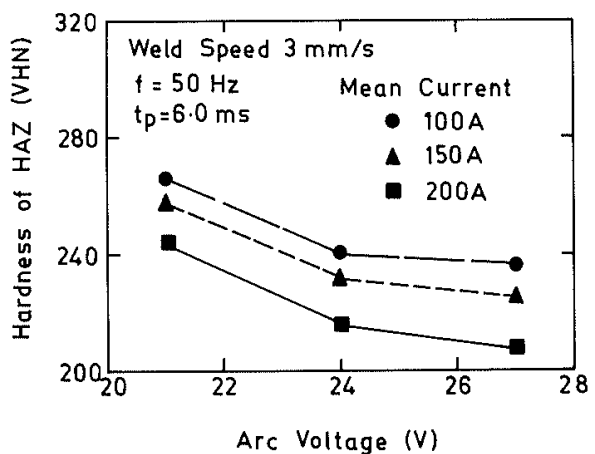

Fig. 22. Effect of arc voltage on the hardness of HAZ.

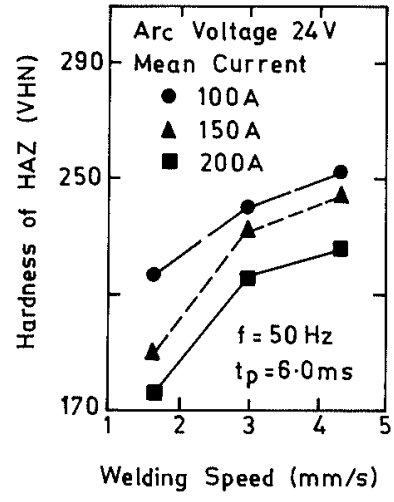

Fig. 23. Effect of welding speed on the hardness of HAZ.

has been found to reduce the hardness of HAZ significantly (Fig. 25), where a lower $\phi$ results at lower arc voltage (Table 2). The increase of arc voltage enhances the energy input as well as the arc length, which increases the area of heating. Both of them may cause reduction in hardness of HAZ due to coarsening of microstructure. From Fig. 25 it may be inferred that the heat distribution by arc length predominates the variation of hardness of HAZ over $\phi$, causing a decrease of hardness inspite of the increase of $\phi$ in contrast to the result shown in Fig. 24, where the arc voltage is constant.

\section{Conclusions}

During pulse current GMAW using flux cored wire the variation in pulse parameters as well as a change in arc voltage and welding speed affect the microstructure and hardness of weld deposit and HAZ, width of HAZ and porosity content of weld deposit. The effect of welding speed on the characteristics of weld deposit and $\mathrm{HAZ}$ are found of usual nature. But, the effects of pulse

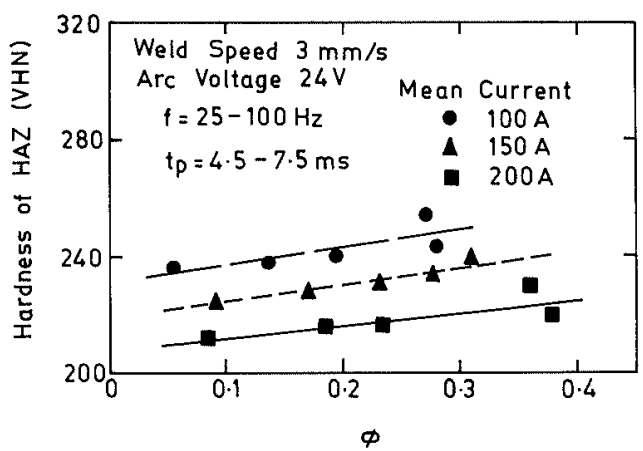

Fig. 24. At a given arc voltage influence of $\phi$ on the hardness of $\mathrm{HAZ}$.

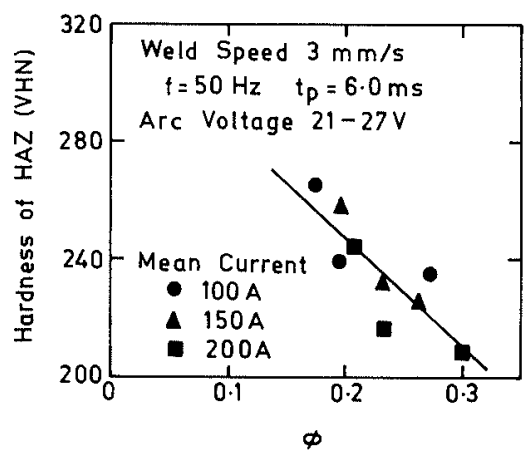

Fig. 25. Under varying arc voltage influence of $\phi$ on the hardness of HAZ.

parameters and arc voltage, those who affect the $I_{\mathrm{p}}$ and $I_{\mathrm{b}}$, on them are found to be linearly correlated to a factor $\phi$, defined as a function of $I_{\mathrm{p}}, I_{\mathrm{b}}, f$ and $t_{\mathrm{b}}$. The width and hardness of HAZ show different linear relationships with the factor $\phi$ when they vary with the change in pulse parameters at a given welding speed and pulse parameter. However, the porosity of weld deposit increases linearly with the enhancement of $\phi$ under any change of pulse parameters and arc voltage. Comparison of the continuous current and pulse current weld beads reveals that a right selection of pulse parameters can improve the weld quality with respect to microstructure, porosity content and hardness of weld bead as well as the width and hardness of HAZ.

\section{REFERENCES}

1) P. K. Ghosh and L. Dorn: Int. J. Joining Mater., 5 (1993), 143.

2) Z. Smati: Met. Constr., 18 (1986), 38R.

3) H. Maruo and Y. Hirata: Study on Pulsed MIG Welding, IIW Doc. SG 212-585-84

4) C. J. Allum and L. Quintino: Met. Constr., 17 (1985), 242. 
5) P. K. Ghosh, P. C. Gupta and R. Somani: Z. Metallkd., 82 (1991), 756.

6) P. K. Ghosh, P. C. Gupta and R. Somani: Int. J. Joining Mater., 3 (1991), 49

7) R. Yeo: Joining Mater., 2 (1989), 68.

8) P. Gough: Joining Mater., 2 (1989), 73.

9) P. Davis: Joining Mater., 2 (1989), 55.
10) R. C. de Medeiros, L. Quintino and J. F. Oliveria Santos: Weld. Met. Fabr., 57 (1989), 79.

11) R. T. Dehoff and F. N. Rhines: Quantitative Microscopy, McGraw Hill, New York, (1968), 177.

12) P. K. Ghosh: Proc. Int. Conf. JOM-7, Helsingor, The European Inst. for the Join. of Mater., (1995), 352. 